\title{
The Psychometric Properties of a Portuguese Version of the Trait-Meta Mood Scale: an Attachment Framework
}

\author{
Joana Cabral ${ }^{1}$ (D) $\cdot$ Tânia Brandão $^{2} \cdot$ Diogo Lamela $^{1} \cdot$ Paula Mena Matos $^{3}$ \\ Published online: 3 July 2020 \\ (C) Springer Science+Business Media, LLC, part of Springer Nature 2020
}

\begin{abstract}
This study examined the psychometric properties of the Portuguese version of Trait Meta-Mood Scale (TMMS). The TMMS is a self-report measure that assesses stable individual differences in the way people attend, discriminate, and repair their mood and emotions. Exploratory and confirmatory factor analyses (CFA) were conducted in a sample of 1070 Portuguese university students, aged 17-30 years. Attachment, coping and rumination measures were used to establish construct validity, and internal consistency was also tested. The CFA failed to gather support for the original three-factor structure. Results suggested that a fourfactor structure, including 26 items tapping suppression, clarity, repair, and difficulties in defensive repression provided the best fit to the data. The four subscales evidenced good internal consistency. In addition, concurrent validity with attachment, coping, and rumination variables was determined. This four-factor structure provided a valid and reliable measure to assess emotion regulation and is proposed to add some comprehensive value to the assessment of emotion regulation under an informationprocessing and attachment framework.
\end{abstract}

Keywords Emotion regulation assessment $\cdot$ TMMS $\cdot$ Psychometrics $\cdot$ Attachment

\section{Introduction}

The interest in emotion regulation has consolidated from its value to explain variations in a myriad of interpersonal processes, namely parenting, interpersonal conflicts and violence (e.g., Low et al. 2018; Siegel 2013). Emotion regulation is also strongly related with personality features, with rumination and predisposition to anxiety and depression (e.g.,

Electronic supplementary material The online version of this article (https://doi.org/10.1007/s10862-020-09817-4) contains supplementary material, which is available to authorized users.

Joana Cabral

joana.cabral@ulp.pt

Paula Mena Matos

pmmatos@fpce.up.pt

1 School of Psychology, Education, and Sports, Lusófona University of Porto, Porto, Portugal

2 Centre for Research in Psychology, Department of Psychology, Autónoma University of Lisbon, Lisbon, Portugal

3 Center for Psychology and Faculty of Psychology and Education Science, University of Porto, Porto, Portugal
Potthoff et al. 2016), and with the ability to cope with adversity, daily stressors, and challenges (e.g., Gross 2013). Despite this interest, the literature in the area maintains intense debates around the definition and theoretical grounding of the construct, which has significant consequences for the operationalization and measurement of the phenomenon. This article presents a study on the factor structure of a Portuguese version of the Trait Meta-Mood Scale (Salovey et al. 1995) that departs from the seminal association between emotional regulation and attachment.

Emotion regulation is defined as the modification of any component of the emotion-generative process (Oatley et al. 2006). These modifications include controlled (i.e., deliberate and conscious) or automatic (i.e., unconscious), intrinsic (regulated by individuals) or extrinsic (regulated by others) processes, can be directed towards decreasing, maintaining, or increasing positive or negative emotions, and can occur before or after emotion response tendencies are activated (Compas et al. 2013; Gross 2013). Emotion regulation varies as a function of individual goals that guide the use of specific strategies.

Under an information-processing framework, emotion regulation is thought as a set of sequential and interdependent dynamics. It involves the management of the attention 
directed to emotions and affect, the ability to discriminate and give them meaning, the processes of modulating emotions and its cognitive correlates, as well as the selection and monitorization of expression and actions triggered by emotions (Fuendeling 1998; Salovey et al. 1995).

Regardless of the diversity among definitions, it is widely accepted that the responsive, attuned and sensitive quality of attachment interactions with primary caregivers are one of the most decisive influences for the development of specific emotion self-regulation strategies and to the consequent individuals differences (Berlin and Cassidy 2003; Bowlby 1969/ 1982; Cassidy 1994; Fuendeling 1998). These early interactions constitute the assisted and co-regulated modes of emotion regulation, which provide the template and structural elements for the self-regulation of emotions later in life (Fuendeling 1998; Esbjørn et al. 2011; Thompson 2008).

The link between attachment and affect regulation is foundational in both fields and attachment is traditionally understood as a system of affect regulation (Mikulincer et al. 2003; Sroufe and Waters 1977). The attachment system and, consequently, emotion regulation are goal corrected (Bowlby 1969/ 1982). In other words, deviations to the desirable proximitybased strategy may develop in order to warrant the best-fitted strategy to both the caregiving context and to the primary goal of security maintenance (Bowlby 1969/1982; Collins et al. 2004; Mikulincer et al. 2003). If caregivers are responsive and attuned when attachment behaviors and related emotions are displayed a primary strategy is developed. This strategy is characterized by comfort with the experience and expression of both positive and negative emotions, a flexible regulation repertoire, and proximity seeking (Main 1990). When attachment interactions are not attuned but instead rejecting, nonresponsive or inconsistently responsive and secondary strategies emerge. These strategies are set as defensive mechanisms and are characterized by an ensemble of difficulties in the experience and expression of emotions (Cassidy 1994; Main 1990; Mikulincer and Shaver 2007).

Research on emotion regulation and emotionally-laden memory sustains the existence of two main "suboptimal" attachment-related strategies of emotion regulation (Van Ijzendoorn et al. 1999). One, the deactivation strategy, reflected in an over-regulation of emotions, which is characteristic of predominantly avoidant-dismissing or avoidantfearful individuals (Fraley and Shaver 1997), and associated with higher levels of suppression, reports of lack of memory and lower emotional expression towards past caregiving memories. One other, the hyperactivation strategy, characteristic of predominantly anxious-ambivalent or preoccupied individuals, and mainly manifested in an under-regulated emotionality, is revealed in intense levels of disruptive emotions regarding caregiving and attachment interactions (Cabral et al. 2012; Dykas et al. 2014; Fuendeling 1998; Mikulincer and Shaver 2007).
In addition, several studies gather evidence for the association between the use of attachment-driven emotion regulation strategies and adjustment and clinical outcomes (Pascuzzo et al. 2013; Kullik and Petermann 2013). Attachment avoidance and attempts to deactivate the attachment needs and related emotions have been associated with increased levels of suppression, alexithymia, and lower levels of emotional awareness and emotional expression (Brenning and Braet 2013; Caldwell and Shaver 2012; Fraley et al. 2000; Garrison et al. 2012; Mallinckrodt and Wei 2005; Monti and Rudolph 2014). Attachment anxiety, mainly associated with hyperactivation of attachment needs and related emotions, has been associated with higher emotional reactivity, higher levels of rumination, and emotional spillover (Brenning and Braet 2013; Cabral et al. 2012; Caldwell and Shaver 2012; Dykas et al. 2014; Fuendeling 1998; Wei et al. 2005). On the contrary, attachment security has been linked to higher positive reappraisal, lower suppression, and lower emotional dysregulation (Karreman and Vingerhoets 2012).

Numerous evidence also support a triangular relationship between attachment, emotion regulation, and coping, supporting the assumption that, while modeling arousal, cognitive appraisal and the modulation of responses to stress and threats, emotion regulation results in preferred coping styles (e.g., Folkman and Moskowitz 2004; Fuendeling 1998; Gross and Thompson 2007; Lopez and Brennan 2000). Attachment avoidance tends to associate with distancing, escape and avoidant coping strategies, whereas attachment anxiety and emotional hyperactivation seem to result in reactive and emotionally engulfed forms of coping (e.g., Cabral et al. 2012; Pascuzzo et al. 2013).

Rumination is yet another process that sheds light on the links between attachment, emotion regulation, and adjustment and clinical outcomes. Rumination can be defined as the individual's tendency to respond to distress by thinking perseveratively about one's feelings and problems (NolenHoeksema et al. 2008) and is conceptualized as a deleterious cognitive strategy, given its association with depressive symptoms, stress, guilt, and anxiety (Garnefski et al. 2004; Martin and Dahlen 2005). Evidence shows that those with higher depressive symptoms tend to direct greater attention to emotions, and to reveal impaired antirumination repair strategies. Hence suggesting that rumination occurs when an elevated attention to emotions is not moderated by the ability to defensively interrupt or repress negative emotions and related thoughts (e.g., Malik et al. 2015).

Despite being a consolidated field of study, a lack of agreement remains around the best candidate indicators to measure emotion regulation (John and Eng 2014). This reflects on a multiplicity of measures, each focused on specific aspects of the phenomenon (e.g., Brandão et al. 2016). Conceptually, emotional regulation shares a common origin with attachment. It dates back to psychoanalytic theory, and finds roots 
in the concept of psychological defense mechanisms. Within the stress and coping tradition, on the other hand, emotion regulation was conceptualized as a set of cognitive and behavioral strategies employed when facing a demanding situation. Hence, being grounded in distinct foundational concepts, while some conceptualizations emphasize non-conscious and non-intentional aspects of emotion regulation, as a heritage from a psychoanalytic tradition, others, inspired by coping literature, focus primarily on deliberated and cognitive efforts to deal with stressful and disruptive emotions (Frederickson et al. 2018).

The majority of measures seem grounded on a cognitive approach, assessing major adaptive and maladaptive strategies of emotion regulation, mainly framed as deliberate cognitive efforts (e.g., Gross and John 2003), or coping strategies as outcomes of emotion regulation (e.g., Garnefski and Kraaij 2007). Also frequently, a bias favouring avoidance and attempts to diminish or control negative emotions tends to dominate, in detriment of an equal emphasis on acceptance and awareness of emotions (Gratz and Roemer 2004). In this scenario, a dearth of measures adopting a comprehensive assessment under an information-processing approach prevails (Bridges et al. 2004).

The research on the specificities of attachment-related emotion regulation particularly suffers from this lack of depth and breadth (i.e., precision and detail), which stands out from the pronounced heterogeneity of measures used within the field. Frequently, either a general measure of emotion regulation or a measure of coping is used. Other studies opt for a combination of measures ranging for ego-resilience to emotional disclosure and awareness (Malik et al. 2015; Zimmer-Gembeck et al. 2017). This imprecision threatens the generalization and theoretical grounding of results. More specifically, it weakens the understanding of the dynamics and consequences of attachment-driven strategies of emotion regulation (Esbjørn et al. 2011). Thus, a parsimonious measure that avoids redundancies and allows to discern between suppression and difficulties in defensive repression is essential to unveil the specificities of deactivation and hyperactivation (Malik et al. 2015).

\section{The Current Study}

Trait-Meta Mood Scale (TMMS) was originally developed, with 48 items, by Salovey et al. (1995) to capture "stable individual differences in people's tendency to attend to their moods and emotions, discriminate clearly among them, and regulate them" (p. 127). After confirmatory factor analysis, a three-factor structure with 30 items showing good fit was proposed, including: attention to feelings (that assessed how attention was directed to emotional states), clarity of feelings (that assessed the ability to give meaning to emotions and to discriminate them), and repair (that assessed the efforts employed to modulate emotions) (Salovey et al. 1995). Even if presented as a measure to assess emotional intelligence, an analysis of the TMMS dimensions and items suggests its value to assess the most relevant dynamics of emotion regulation under an information-processing framework (e.g., Fuendeling 1998).

The 30-item version of the measure has been translated and adapted to different countries (Aksöz et al. 2010; Pedrosa et al. 2014; Otto et al. 2001). Three studies used samples of university students, two used a sample of secondary students, and one used a community sample, aged 15 to 79 years old. Although confirming the three-factor structure, the items retained vary among studies and from the original 30-item version, both in number and in composition. One study found evidence suggesting a four-factor structure; however, did not describe or explore the fourth dimension (Palmer et al. 2003). One study testing a Portuguese 24-item version of the TMMS was found, though the authors did not test its factor-structure, only gathering support for its reliability and construct validity (Queirós et al. 2005). In addition, a major limitation was found in Spanish and Portuguese versions, since negative items were positively worded, which significantly affected the construct and content equivalence, favouring the bias for avoidance and control over negative emotions (Pedrosa et al. 2014; Queirós et al. 2005).

The general goal of the current study was to explore the factor structure and psychometric properties of a Portuguese version of TMMS, starting from the original 48 items. As discussed, the evidence and literature on the link between attachment, emotion regulation, and clinical and adjustment outcomes (e.g., anxiety and depression) is compromised by relevant measurement and methodological limitations. Among them is the difficulty in measuring the specificities of the emotional regulation strategies of deactivation and hyperactivation associated with attachment organizations (Malik et al. 2015). In an attempt to contribute to overcome these limitations and with the expectation of finding a factor structure that would detect the dynamics of attachmentdriven emotional regulation, information-processing and attachment approaches were used as theoretical frameworks. The test of the factor structure was followed by analyses of reliability and construct validity for the final factor solution.

\section{Method}

\section{Participants and Procedure}

Participants were all freshmen and recruited in several schools of one of the largest universities in Portugal (Arts, Human Sciences, Engineering, Law, Economics and Management, Exact Sciences, and Health Sciences). Bebore data collection, 
we first contacted the department chairs in order to describe the research and asked for their permission to include students enrolled in the courses of their department. After acceptance, department chairs indicated a class in which students could be invited to participate. Subsequently, members of the research team approached the students in the classrooms, orally presented the research's aim and ethical procedures, and asked for voluntary and anonymous participation. Students who agreed to participate were asked to read and sign the informed consents' form. Assessment protocols were then administered during classes. No compensation was offered. The PhD scientific committee and institutional review board at the research site approved the study prior to its conduction.

\section{Measures}

Trait Meta-Mood Scale (TMMS) The TMMS (Salovey et al. 1995) was originally composed by three subscales: Attention (21 items; e.g., "it is usually a waste of time to think about your emotions"), Clarity (15 items; e.g., "I am usually very clear about my feelings"), and Repair (12 items; e.g., "I try to think good thoughts no matter how badly I feel"). Items are scored on a 5-point Likert scale from 1 (strongly disagree) to 5 (strongly agree); higher scores reflect greater attention to feelings and ability to discriminate and regulate emotions. The subscales of the 48-item version showed very good internal consistency (Cronbach's alphas ranged from .82 to .87 ), as well as satisfactory concurrent and discriminant validity (Salovey et al. 1995).

Father and Mother Attachment Questionnaire (FMAQ) The FMAQ (Gouveia and Matos 2011; Matos and Costa 2001) is a 30 -item instrument that measures three main dimensions of attachment: Inhibition of Exploration and Individuality (10 items; e.g., "My parents discourage me when I want to try new things"), Quality of Emotional Bond (10 items; e.g., "I know that I can count on my parents whenever I need them), and Separation Anxiety (10 items; e.g., "I am afraid of being left alone if I lose my parents"). Items are rated on a 6-point Likert scale (from 1 'completely disagree' to 6 'completely agree'). For each item, participants are asked to report to their relationship with each parent independently. Higher scores in each subscale reflect greater presence of the assessed attachment domain. In the current dataset, Cronbach's alpha ranged from .85 to .93 , for the relationship with mother, and from .86 to .89 for the relationship with father. For each of the dimensions data from attachment to mother and father was used to calculate the equivalent composite variables measuring attachment to both parents.

Romantic Attachment Questionnaire (RAQ) The 21-item RAQ (Matos and Costa 2001) measures the attachment representations regarding the current romantic relationship with four subscales: Trust (5 items; e.g., "I know that I can count on my boyfriend/girlfriend whenever I need him/her"), Dependence (5 items; e.g., "When I can't be with my boyfriend/girlfriend, Ifeel abandoned"); and Avoidance (5 items; e.g., "When I have a problem, I prefer being alone instead of being with my boyfriend/girlfriend"), and Ambivalence (6 items; e.g., "Sometimes I fell he/she is fundamental in my life; sometimes I don't."). Each item was answered on a 6-point Likert scale (from 1 'completely disagree' to 6 'completely agree'). Higher scores in each subscale represent higher levels of the measured domain. In the current study, Cronbach's alphas of the four scales ranged from .81 to .91 .

COPE Inventory (COPE) The COPE (Carver et al. 1989; Portuguese version by Cabral and Matos 2010) is a selfreported measure of coping strategies. The Portuguese version of 24-items comprises four subscales: Active/Reflexive (7 items; e.g., "I take direct action to get around the problem"), Seeking Support (5 items; e.g., "I discuss my feelings with someone"), Avoidant (7 items; e.g., "I pretend that the situation didn't really happen"), and Positive Reframing (5 items; e.g., "I look for something good in what is happening"). Items are scored on a 5-point Likert scale (from 1 'I usually don't do this at all' to 4 'I usually do this a lot'). For each subscale, higher scores reflect higher levels of the assessed coping strategy. In the current sample, Cronbach's alphas ranged from .66 to .80 .

Ruminative Responses Scale (RRS) The RRS (Treynor et al. 2003; Portuguese version by Cabral and Matos 2010) assesses individuals' tendencies to ruminate. In the current study, the 14-item Brooding subscale (e.g., "Think 'I won't be able to concentrate if I keep feeling this way") was used. Items are scored on a 6-point Likert scale from 1 (totally disagree) to 6 (completely agree). Good internal consistency was found in the present study (Cronbach's $\alpha=.89$ ).

\section{Translation of the TMMS}

The TMMS was translated to Portuguese according to the guidelines of the International Test Commission and a "forward translation" design (Hambleton et al. 2005). A translation of the TMMS was conducted by the first author of this study. The equivalence of the source and target versions was then discussed with one specialist, fluent in Portuguese and English, and familiar with the construct. The discussion focused on: (i) conceptual or construct equivalence (the degree in which items represented the original formulation and theoretical constructs), (ii) content equivalence (the degree to which items had the same meaning in both cultures), as well as semantic and idiomatic equivalence (the degree to which the items were as semantically equivalent as possible and idiomatic expressions were adequately translated). The 
translated version was then submitted to two "think-aloud" groups of eight and 10 young adults in order to ensure face validity (Hambleton et al. 2005). After completion, participants were asked to share and discuss their impressions regarding the: (i) accessibility of language; (ii) intelligibility of items, instructions and response scale; and (iii) meaning and interpretation of items. Minor changes in items semantics were considered following participants feedback.

\section{Data Analytic Strategy}

The database was checked for the presence of univariate and multivariate outliers, using z-scores, scatter-plots, q-q plots, standardized residuals and Mahalanobis distance. Potential outliers were identified when z-scores and Mahalanobis distance were above critical values (|3.5| for Z-scores). Error outliers were sorted from interesting outliers and removed based on qualitative analysis of consistency and accuracy responses patterns. Further criteria and procedures to check for influential outliers included Cook's $\mathrm{D}_{\mathrm{i}}$, and running the models with and without the presence of potential outliers (Field 2013; Kline 2015). Missing data was handled using the Expectation-Maximization (EM) method, since the pattern was completely at random and the number of missing values was small (less than 5\%) (Tabachnick and Fidell 2007).

We first conducted a confirmatory factor analysis (CFA; AMOS 18.0) on the total sample $(N=1070)$ testing the threefactor structure (i.e., attention, clarity, and repair) with the original 48-item version of the TMMS. The estimation method used was maximum likelihood. Multiple measures were used to determine the goodness-of-fit of the estimated model: the chi-square/df statistic, the Bentler comparative fit index (CFI), the goodness of fit index (GFI), and the root mean square error of approximation (RMSEA). Chi-square/df values between .2 and 5, CFI and GFI greater than .90 and .95 , and RMSEA lower than .08 and .05 indicate acceptable and good model fit, respectively. The significance of the chisquare test was not considered as an indicator of fit, since it is affected by the (large) size of the sample (Hooper et al. 2008).

The attempt to confirm the original version revealed a lack of fit. Moreover, considering the lack of consistency on previous factor structure studies, a further examination was carried out. The complete dataset $(\mathrm{N}=1070)$ was randomly split in two different subsets: an examination subsample and a validation subsample. This two-step procedure is commonly used in large samples and is useful when no other independent or new sample is timely available (e.g., Wróbel et al. 2019). EFA (Exploratory Factor Analysis) was performed on the examination half $(n=537)$, in order to explore an alternative organization of items. A CFA using the other half $(n=533)$ was then conduct to confirm the structure suggested by the EFA.

Principal components analysis and principal axis factoring were performed on the 48 items and resulted in similar results.
Data suitability was confirmed by Kaiser-Meyer-Olkin $(\mathrm{KMO})$ value $(\mathrm{KMO}=.86)$ and the Bartlett's test of sphericity $(p<.001)$. Four criteria were used to determine the optimal factor solution: (a) Cattell's scree test; (b) eigenvalues above 1; (c) results of the Parallel Analysis Engine; and (d) 5\% of incremental variance accounted for each added component (Marôco 2011; Patil et al. 2007). Since no solely consensual rule of thumb, regarding factor loadings, can be found for decisions to retain or delete items, a 40 cut-off was considered for EFA - in a less strict exploratory approach - and a more stringent cut-off of .45 was employed for CFA (Tabachnick and Fidell 2007). Qualitative analysis of items and dimensionality was based on attachment and information-processing frameworks of emotion regulation, as well as on the original theoretical proposal.

\section{Results}

\section{Factor Structure of the TMMS}

Exploratory Factor Analysis Following the poor model fit $\left(\chi^{2}\right.$ $(1077)=7775.33 ; p=.000 ; \chi^{2} / \mathrm{df}=7.22 ; \mathrm{CFI}=.58$; $\mathrm{GFI}=.69$; RMSEA $=.08,90 \% \mathrm{CI}(.076, .080)$, pclose $<.05)$ found when CFA was performed, an EFA was conducted on the examination subsample. Scree-plot and eigenvalues criteria indicated six components, whereas results of the Parallel Analysis Engine and 5\% of incremental variance criteria indicated the retention of four components. These two alternative factor solutions were further compared. Factors 3, 4, 5 and 6, from the six-factor structure, gathered items from all original dimensions, with numerous cross-loadings, which revealed a significant overlap between the constructs and hence prevented a theoretical interpretation. In contrast, the four-factor solution showed a lower number of cross-loadings between factors and supported a better theoretical interpretation of the data. In addition, the four-factor solution showed higher coherence with the original organization of items (see Table 1 of the Supplementary Material). As a result, the four-factor model was retained and further inspected. Eighteen items were excluded due to loadings below .40, cross-loadings, and item's theoretical dissonance with component (excluded items are listed in Table 2 of Supplementary Material).

The 30 remaining items and four factors were qualitatively analyzed in order to investigate their dimensionality and to assign them a coherent description. Factor 1 was labelled as "suppression" and was composed of items 4, 7, 8, 14, 29, 30, $31,38,44$, and 46 . The decision to label this dimension as suppression resulted from the fact that all items, though originally from attention, were negatively formulated (e.g., "I never give into my emotions"), suggesting an attempt to avoid, devalue, and diverge attention from emotions seen as threats. 
Factor 2, gathering most items from the original clarity dimension, maintained its designation and was composed by items $9,12,19,26,28,37,42,45$, and 48. Factor 3 also maintained the original items from the repair dimension, also maintaining its label - 2, 16, 23, 36, and 43. Factor 4 was labeled "difficulties in defensive repression" and gathered negative items $5,6,13,17,27$, and 39 - originally from repair. These set of items suggested a particular difficulty in emotion regulation, specifically to avoid emotion spill-over, rumination, and their disruptive impact on mood and thought.

Confirmatory Factor Analysis The four-factor model was subsequently tested in the second subsample through CFA using maximum likelihood estimation. First, each individual factor or subscale was tested based on results from EFA. Four items that presented low loadings $(<.45)$ were deleted (one from repair, one from difficulties in defensive repression, and two from suppression). Some error correlations were considered, following suggestions by modification indices, when justified by semantic similarity. Results for the final models of each subscale showed close fit to the data (see Table 1).

A 4-factor final solution with 26-items and correlated error terms (modifications and fit indices are resumed in Tables 1 and Table 3 shows initial model fit) showed acceptable fit to the data $\left(\chi^{2}(285)=716,675 ; p=.000 ; \chi^{2} / \mathrm{df}=2,52\right.$; $\mathrm{CFI}=.90 ; \mathrm{GFI}=.91$; RMSEA $=.05,90 \%$ CI $(.049-.058)$, pclose $=.126$ ). Factor loadings were all above .50 , with the exceptions of three items with loadings of 49 (see Table 2).

The goodness of fit was also established by comparison with two 3-factor alternative models: a 3-factor model with our retained 26 items and a 3 -factor model with the originally proposed 30 items. All fit indices were superior for the 4factor structure, even when the models without modifications (i.e., exclusion of low loading items and inclusion of error correlations) were considered (see Table 3).

\section{Reliability and Construct Validity}

Cronbach's $\alpha$ coefficients were used to assess the internal consistency. Values between .60 to .70 and above .70 indicate acceptable and good of reliability, respectively (Nunnally and Bernstein 1994). Internal consistencies and intercorrelations between factors are presented in Table 4. The Cronbach's alphas were $.76, .84, .76$, and .73 for the suppression, clarity, repair, and difficulties in defensive repression factors, respectively. In addition, the low and moderate intercorrelations between factors suggested the multidimensional nature of the TMSS.

To assess the construct validity of the TMMS 4-factor version, we conducted Pearson correlations between the four factors and measures of attachment, coping, and rumination. Results are presented in Table 5. Overall, associations were in the expected direction.

Associations between the TMMS and Attachment Variables All measures of attachment to parents were correlated with the TMMS subscales. The inhibition of exploration and individuality was positively correlated with suppression and difficulties in defensive repression factors, and negatively associated with clarity and repair factors. On the other hand, the quality of emotional bond subscale revealed a negative and significant association with both suppression and difficulties in defensive repression factors, and a positive association with clarity and repair factors. Finally, no significant correlation was found between the separation anxiety subscale and suppression and repair factors; however, significant correlations were found with clarity (negative) and with difficulties in defensive repression (positive) factors.

Considering the associations between the TMMS factors and romantic attachment dimensions assessed by the RAQ, our results revealed that the trust subscale was positively correlated with the clarity and repair factors, and negatively

Table 1 Fit Indices for local adjustment for each dimension in confirmatory factor analyses

\begin{tabular}{|c|c|c|c|c|c|c|c|}
\hline Dimensions & $x^{2}$ & df & $\mathrm{p}$ & $\begin{array}{l}x^{2} / \\
d f\end{array}$ & CFI & GFI & $\begin{array}{l}\text { RMSEA } \\
(90 \% \text { CI) pclose }\end{array}$ \\
\hline Suppression items: $4,7,8,14,29,30,31,38,44,46$ & 230.53 & 35 & .000 & 6.59 & .84 & .91 & $.10(.091, .012), .000$ \\
\hline $\begin{array}{l}\text { Suppression } \\
\text { excluding items } 14,30 \text { error terms correlated: } 7-8-38 ; 29-31\end{array}$ & 57.59 & 17 & .000 & 3.39 & .96 & .97 & $.07(.049, .087), .065$ \\
\hline Clarity items: $9,12,19,26,28,37,42,45,48$ & 53.22 & 22 & .000 & 2.42 & .98 & .98 & $.05(.034, .071), .411$ \\
\hline Regulation items: $2,16,23,36,43$ & 20.37 & 5 & .001 & 4.07 & .98 & .99 & $.076(.045, .123), .089$ \\
\hline Regulation excluding item 36 & 4.11 & 2 & .128 & 2.05 & 1.00 & 1.00 & $.045(.001, .108), .458$ \\
\hline Difficulties in Defensive Repression items: 5,6,13,17,27,39 & 4.94 & 19 & .162 & 1.31 & .99 & .99 & $.046(.000, .048), .966$ \\
\hline $\begin{array}{l}\text { Difficulties in Defensive Repression excluding items } \\
13 \text { error terms correlated: } 26-45 ; 19-37-28-48\end{array}$ & 3.66 & 5 & 600 & .73 & 1.00 & 1.00 & $.00(.001, .051), .945$ \\
\hline
\end{tabular}

$\chi^{2}=$ Chi-square; $\mathrm{df}=$ degrees of freedom; $C F I$ comparative fit index, GFI goodness of fit index, RMSEA root-mean-square error of approximation, $C I$ confidence intervals 
Table 2 Final dimensions and items

\begin{tabular}{|c|c|c|c|}
\hline Dimension & Item & Loading CFA & Original dimension \\
\hline \multirow[t]{8}{*}{ Suppression } & 4 - People would be better off if they felt less and thought more. & .52 & Attention \\
\hline & 7 - I don't think it's worth paying attention to your emotions. & .54 & Attention \\
\hline & 8 - I don't usually care much about what I'm feeling. & .49 & Attention \\
\hline & 29 - One should never be guided by emotions. & .65 & Attention \\
\hline & 31 - I never give into my emotions. & .54 & Attention \\
\hline & 38 - I don't pay much attention to my feelings. & .57 & Attention \\
\hline & 44 - Feelings are a weakness humans have. & .62 & Attention \\
\hline & 46 - It is usually a waste of time to think about your emotions. & .67 & Attention \\
\hline \multirow[t]{9}{*}{ Clarity } & 9 - Sometimes I can't tell what my feelings are. & -.56 & Clarity \\
\hline & 12 - I am rarely confused about how I feel. & .51 & Clarity \\
\hline & 19 - I can never tell how I feel. & -.50 & Clarity \\
\hline & 26 - I am often aware of my feelings on a matter. & .53 & Clarity \\
\hline & 28 - I am usually confused about how I feel. & .61 & Clarity \\
\hline & 37 - I can’t make sense out of my feelings. & -.68 & Clarity \\
\hline & 42 - I am usually very clear about my feelings. & -.78 & Clarity \\
\hline & 45 - I usually know my feelings about a matter. & -.60 & Clarity \\
\hline & 48 - I almost always know exactly how I feel. & .76 & Clarity \\
\hline \multirow[t]{4}{*}{ Repair } & 2 - I try to think good thoughts no matter how badly I feel. & .80 & Repair \\
\hline & 16 - Although I am sometimes sad, have a mostly optimistic outlook. & .49 & Repair \\
\hline & 23 - When I become upset I remind myself of all the pleasures in life. & .62 & Repair \\
\hline & 43 - No matter how badly I feel, I try to think about pleasant things. & .77 & Repair \\
\hline \multirow[t]{5}{*}{ Difficulties in defensive repression } & 5 - I usually don't have much energy when I'm sad. & .51 & Repair \\
\hline & 6 - When I'm angry, I usually let myself feel that way. & .49 & Repair \\
\hline & 17 - When I am upset I realize that the "good things in life" are illusions. & .51 & Repair \\
\hline & 27 - When I'm depressed, I can't help but think of bad thoughts. & .67 & Repair \\
\hline & 39 - Whenever I'm in a bad mood, I'm pessimistic about the future. & .78 & Repair \\
\hline
\end{tabular}

associated with suppression and difficulties in defensive repression. In contrast, the avoidance and ambivalence subscales were negatively associated with repair and clarity and positively correlated with suppression and difficulties in defensive repression factors (only for ambivalence). The dependence subscale of the RAQ was negatively correlated with the suppression and positively with difficulties in defensive repression dimensions of emotion regulation.

\section{Associations between the TMMS and Coping and Rumination}

Variables Active/reflexive coping, support-seeking coping, and positive reframing subscales of the COPE were negatively associated with suppression and difficulties in defensive repression factors and positively correlated with clarity and repair. In contrast, the avoidant coping subscale showed a negative association with clarity and repair factors and positive associations with suppression and difficulties in defensive repression factors. Finally, the rumination subscale of the RSS showed a positive and moderately high association with difficulties in defensive repression, and was negatively correlated with clarity and repair subscales.

\section{Discussion}

Despite the increased interest in emotion regulation, some lack of consensus remains, both in terms of construct definition and in terms of the best candidates for measurable indicators of emotion regulation processes and dynamics (e.g., Gratz and Roemer 2004). The present study aimed to examine TMMS as an attachment and information-processing oriented measure of emotion regulation. The psychometric properties of the proposed Portuguese version were tested for factor structure, reliability, and construct validity, in a sample of undergraduate students. The results of the exploratory and confirmatory factor analysis suggested a factor structure that differs slightly from the original structure, replicated in following studies with the measure, by adding a fourth factor to the three commonly proposed. This alternative structure seems valuable to assess attachment-driven emotion regulation dynamics.

A first attempt to replicate the original three-factor structure failed, showing a poor fit to the data and suggesting the need for a more exploratory approach. Results from exploratory factor analysis, using half of the total sample, suggested four 
Table 3 Fit Indices for CFA of 4-factor and 3-factor models

\begin{tabular}{lllllllrr}
\hline Model & $\chi^{2}$ & $\mathrm{df}$ & $\begin{array}{l}\chi^{2} / \\
\mathrm{df}\end{array}$ & CFI & GFI & $\begin{array}{l}\text { RMSEA } \\
(90 \% \text { CI }) \text { pclose }\end{array}$ & $\begin{array}{c}\Delta \chi^{2} \\
(\mathrm{df})\end{array}$ \\
\hline Final 4-factor with 26 items & $716,68 * * *$ & 285 & 2,52 & .90 & .91 & $.053(.049, .058) .126$ & - \\
Initial 4-factor with 26 items & $1017.89 * * *$ & 293 & 3.47 & .84 & .86 & $.068(.064, .074) .000$ & $301.21(8) * * *$ & 1133.79 \\
3-factor with 26 items & $1290.21^{* * *}$ & 296 & 3.83 & .81 & .77 & $.079(.075, .084) .000$ & - & 1400.21 \\
3-factor with 30 itens & $1836.98 * * *$ & 402 & 4.57 & .74 & .77 & $.082(.079, .086) .000$ & - & 1962.98 \\
\hline
\end{tabular}

$\chi^{2}=$ Chi-square; $\mathrm{df}=$ degrees of freedom; $C F I$ comparative fit index, GFI goodness of fit index, RMSEA root-mean-square error of approximation, $C I$ confidence intervals; $\Delta \chi^{2}(\mathrm{df})=$ change in Chi-square and degrees of freedom; AIC Akaike Information Criterion; *** $p<.001$

factors, instead of three. This alternative organization was then tested, using confirmatory factor analysis, in the other half of the sample, and revealed acceptable fit. However, this structure is not seen as contradictory to the one recommended by the original authors. The factor structure found maintained the three original dimensions, namely attention, in this case formulated as suppression (gathering items from attention originally negatively formulated), clarity, and repair. These three dimensions continued to capture attentional processes (an attempt to avoid, devalue and suppress emotions seen as threatening), the ability to discriminate emotional states and efforts to modulate emotions. Low to moderately low interscale correlations suggested that the four dimensions capture different, although related, aspects of the emotion regulation process.

An additional dimension, gathering items originally from repair and labelled as difficulties in defensive repression emerged. Items loading in this factor seem to assess the difficulty in interrupting the disruptive effect of emotional spillover and the ruminative thoughts that result from it. This dimension reveals an under-regulated regulation of emotions and suggests a hyperactivation attachment-based strategy. It should be noted that among the covariances imposed between factors on the final model, only the one between suppression and difficulties in defensive repression was non-significant.

The relevance of an independent assessment of suppression and difficulties in defensive repression is supported both empirically and by the literature (Esbjørn et al. 2011; Malik et al. 2015). These processes can be seen as two poles of a continuum with regard to the defensive management of attention directed to emotions, but are nonetheless qualitatively different (for example, Fuendeling 1998; Malik et al. 2015). In addition, these defense efforts may correspond to distinct strategies or configurations of emotional regulation, which in turn are associated with distinct strategies and dimensions of attachment (Mikulincer et al. 2003). This was corroborated by the pattern of correlations found between these emotion regulation dimensions and attachment (discussed below).

A series of correlations with attachment, coping, and rumination, considered as concurrent or related constructs, gathered evidence for construct validity. In the case of correlations with the attachment variables, the results were in line with previous evidence and suggested that attachment (in)security is reflected in the more adaptive or maladaptive character of emotion regulation (for example, Caldwell and Shaver 2012; Monti and Rudolph 2014). Furthermore, they also corroborate the existence of distinct emotion regulation strategies resulting from equally distinct attachment configurations (e.g., Cabral et al. 2012; Dykas et al. 2014; Malik et al. 2015). Higher levels of quality of emotional bond, an indicator of attachment security, were associated with a more adaptive approach to emotion regulation; namely with higher levels of clarity and repair and lower levels of suppression and of difficulties in defensive repression. In turn, attachment avoidance, evidenced by low levels of quality of emotional bond, was as expected associated with increased suppression. In turn, higher levels of separation anxiety, an indicator of attachment anxiety, were associated with increased levels of difficulties in defensive repression but unrelated with suppression.

Correlations between emotion regulation and romantic attachment also offered the possibility of identifying distinct

Table 4 Reliability and intercorrelations between the four TMMS dimensions

\begin{tabular}{lcrr}
\hline & 1 & 2 & 3 \\
\hline Suppression & - & & .76 \\
Clarity & $-.205^{* * *}$ & - & .84 \\
Regulation & $-.169^{* * *}$ & $.216^{* * *}$ & .76 \\
Difficulties in Defensive Repression & $.079^{* *}$ & $-.359^{* *}$ & - \\
\hline
\end{tabular}

$* * p<.01 ; * * * p<.001$ 
Table 5 Correlations between TMMS, attachment, coping, and rumination

\begin{tabular}{|c|c|c|c|c|}
\hline & Suppression & Clarity & Repair & $\begin{array}{l}\text { Difficulties in } \\
\text { Defensive Repression }\end{array}$ \\
\hline Inhibition of Exploration and Individuality & $.213 * * *$ & $-.254 * * *$ & $-.128 * * *$ & $.236 * * *$ \\
\hline Quality of Emotional Bond & $-.172 * * *$ & $.165^{* * *}$ & $.165^{* * *}$ & $-.100 * * *$ \\
\hline Separation Anxiety & -.013 & $-.098 * * *$ & -.022 & $.223 * * *$ \\
\hline Trust & $-.337 * * *$ & $.242 * * *$ & $.176^{* * *}$ & $-.141 * * *$ \\
\hline Dependence & $-.133 * * *$ & -.044 & -.012 & $.249 * * *$ \\
\hline Avoidance & $.422 * * *$ & $-.187 * * *$ & $-.117 * * *$ & .008 \\
\hline Ambivalence & $.240 * * *$ & $-.295 * * *$ & $-.134 * * *$ & $.364 * * *$ \\
\hline Active/Reflexive & $-.144 * * *$ & $.204 * * *$ & $.338 * * *$ & $-.153 * * *$ \\
\hline Seeking Support & $-.394 * * *$ & $.120 * * *$ & $.263 * * *$ & $-.091 * *$ \\
\hline Avoidant & $.317 * * *$ & $-.275^{* * *}$ & $-.160 * * *$ & $.296 * * *$ \\
\hline Positive Reframing & $-.098 * *$ & $.164 * * *$ & $.510^{* * *}$ & $-.332 * * *$ \\
\hline Rumination & .053 & $-.406^{* * *}$ & $-.223 * * *$ & $.568 * *$ \\
\hline
\end{tabular}

$* * p<.01 ; * * * p<.001$

attachment-driven approaches to emotion regulation. Being able to trust, emotionally connect, and engage within a relationship with an intimate partner was associated with more adaptive emotion regulation. Results seem to reflect a security-based or primary strategy, characterized by a balanced attention directed towards emotional states, a higher ability to discriminate them, to give them meaning, and to repair negative affective states. In addition, feeling securely attached also seems to be associated with a lower engagement with suppression and less difficulties in defensive repression of disruptive emotions. On the contrary, those who avoid or feel ambivalent regarding the romantic partner or relationship seem to have more trouble dealing with their emotions. As supported by previous evidence (e.g., Ávila et al. 2011; Mikulincer and Shaver 2007) a predominantly avoidant attachment seems to be related to highly suppressive emotion regulation and to a lower capacity to discriminate and repair emotional states; which in turn suggests the use of a strategy of deactivation and over-regulation. Feeling highly dependent on the romantic partner and an anxious concern about separation and loss appears associated with difficulties in defensive repression of disruptive emotions and with a lower engagement in suppression. These results are in line with previous evidence and suggests the employment of an under-regulated or hyperactivation strategy (Ávila et al., 2011; Brenning and Braet 2013; Caldwell and Shaver 2012; Wei et al. 2005). Interestingly, dependence, the characteristic most commonly associated with anxious attachment, does not seem to be associated with less clarity in the discrimination of emotions and with a greater difficulty in repairing them, which contradicts some of the evidence mentioned above.

As for attachment ambivalence, results support that worriedness about the value of intimacy and doubts concerning personal and partner feelings are associated with an ambivalent approach to emotion regulation. While, such as avoidance, ambivalence is associated with greater suppression, unlike avoidance, it is also associated with greater difficulties in defensive repression. Among the dimensions of romantic attachment, ambivalence appears as the most strongly associated with difficulties in emotion regulation, namely showing the highest association with difficulties in clarity and repairing abilities. The results suggest that the deactivation and hyperactivation strategies, although distinct, are not mutually exclusive. Rather, when combined, their disruptive and deleterious effects are amplified. These evidences are in line with previous research (Cabral et al. 2012) and points towards the importance of more comprehensive and detailspecific approaches to the assessment of both attachment and related emotion regulation dynamics. This is in line with concerns about the importance of considering the specificities of an ambivalent attachment experience, or a fearful attachment style, as well as its particular consequences for personality functioning and adaptability (e.g., Bartholomew and Horowitz 1991; Fonagy and Luyten 2012).

Results on the association between emotion regulation and coping were all in the expected direction, generally revealing that a less adaptive emotion regulation is associated with less constructive coping strategies. More specifically, higher levels of suppression and difficulties in defensive repression are associated with an increased use of avoidant coping and a lower use of active-reflexive coping. These results are not only theoretically consistent but also empirically supported by other studies (e.g., Cabral et al. 2012; Brenning and Braet 2013; Lopez and Brennan 2000; Mallinckrodt and Wei 2005; Mikulincer et al. 2003; Monti and Rudolph 2014).

Finally, the results regarding the association between emotion regulation and rumination showed that, as expected, higher levels of difficulties in defensive repression are 
associated with increased rumination, as well as with difficulties in discriminating and repairing emotions. These evidences are again in line with the previous discussed research (Boyes et al. 2016; Malik et al. 2015).

Some limitations to this study must be considered. Firstly, our results are specific to university emergent adults and generalization to other age groups should be made with caution. Future research should include representative samples (e.g., regarding age, gender and occupational status) in order to gather evidence for the stability and utility of the proposed structure with other populations. Secondly, the crosssectional and correlational nature of our study, based in selfreport, advises that further research should longitudinally separate the attachment and emotion regulation assessments and include multiform assessment of emotion regulation. Finally, given the need to guarantee a parsimonious protocol, other measures were not included, neither as an alternative measure of emotion regulation, nor for the assessment of unrelated constructs, which prevented the concurrent and divergent validity test.

The four-factor structure, as well as the dimension of difficulties in defensive repression, were to our best knowledge identified in this study for the first time. Future studies should focus on gathering further support for the four-factor structure and for its added value, for the detection of attachment-driven strategies of emotion regulation. As a suggestion for future research, person-oriented analyses could help to uncover some of the specificities in the configurations of attachmentrelated emotion regulation, suggested by the present results. As an example, the use of clusters or latent class analysis would allow to explore combinations between the various features of attachment and emotion regulation, namely patterns of attachment and emotion regulation. In addition, associations between the latter and measures of clinical outcomes and adjustment, such as personality traits, anxiety, depression and well-being, would allow a better overview and understanding of the more or less adaptive character of attachment-driven emotional regulation strategies. This finegrained understanding of the dynamic associations between personality, adjustment and mental health is crucial to inform clinical strategies better adapted to promoting changes in attachment and emotional regulation (Frederickson et al. 2018).

The current study provided evidence for the internal consistency and validity of the TMMS and gathered support for an alternative 4-factor structure of the measure. The four dimensions were internally consistent, seemed to cover distinct dynamics, and were related to theoretically relevant constructs, namely attachment, coping, and rumination. The findings support the relevance of the proposed factor structure. In addition, our findings contribute for the informative and hermeneutic value of an approach on the assessment of emotional regulation that is grounded on an attachment theoretical framework. At the same time, it was possible to gather evidence for the existence of attachment-driven emotion regulation, as well as for their association with adjustment and clinical outcomes that are relevant for mental-health and wellbeing.

Funding Information This study was funded by Fundação para a Ciência e Tecnologia (PTDC/PSI/65416/2006). No competing or conflict of interests to declare.

\section{Compliance with Ethical Standards}

First author has received research grants Fundação para a Ciência e Tecnologia (FCT).

Conflict of Interest Joana Cabral, Tânia Brandão, Diogo Lamela and Paula Mena Matos declare that have no conflict of interest.

Experiment Participants All procedures performed in studies involving human participants were in accordance with the ethical standards of the institutional and national research committee and with the 1964 Helsinki declaration and its later amendments or comparable ethical standards. Informed consent was obtained from all individual participants included in the study.

\section{References}

Aksöz, I., Bugay, A., \& Erdur-Baker, Ö. (2010). Turkish adaptation of the trait Meta-mood scale. Procedia - Social and Behavioral Sciences, 2, 2642-2646. https://doi.org/10.1016/j.sbspro.2010.03. 387.

Ávila, M., Cabral, J., \& Matos, P. M. (2011). Parental attachment and romantic relationships in emerging adults: The role of emotional regulation processes. Family Science, 2(1), 13-23.

Bartholomew, K., \& Horowitz, L. M. (1991). Attachment styles among young adults: A test of a four-category model. Journal of Personality and Social Psychology, 61, 226-244.

Berlin, L. J., \& Cassidy, J. (2003). Mothers' self-reported control of their preschool children's emotional expressiveness: Associations with infant-mother attachment and children's emotion regulation. Social Development, 12, 477-495.

Bowlby, J. (1969/1982). Attachment and loss, Vol 1: Attachment (2nd). New York: Basic Books.

Boyes, M. E., Hasking, P. A., \& Martin, G. (2016). Adverse life experience and psychological distress in adolescence: Moderating and mediating effects of emotion regulation and rumination. Stress and Health, 32(4), 402-410. https://doi.org/10.1002/smi.2635.

Brandão, T., Tavares, R., Schulz, M. S., \& Matos, P. M. (2016). Measuring emotion regulation and emotional expression in breast cancer patients: A systematic review. Clinical Psychology Review, 43, 114-127. https://doi.org/10.1016/j.cpr.2015.10.002.

Brenning, K. M., \& Braet, C. (2013). The emotion regulation model of attachment: An emotion-specific approach. Personal Relationships, 20, 107-123. https://doi.org/10.1111/j.1475-6811.2012.01399.x.

Bridges, L. J., Denham, S. A., \& Ganiban, J. M. (2004). Definitional issues in emotion regulation research. Child Development, 75, 340-345.

Cabral, J., \& Matos, P. M. (2010). Estudo de adaptação do COPE Inventory. Teste de uma estrutura alternativa [COPE-Inventory: An alternative factor structure]. Psicologia, 22, 49-71.

Cabral, J., Matos, P. M., Beyers, W., \& Soenens, B. (2012). Attachment, emotion regulation and coping in Portuguese emerging adults: A test 
of a mediation hypothesis. The Spanish Journal of Psychology, 15, $1000-1012$

Caldwell, J. G., \& Shaver, P. R. (2012). Exploring the cognitiveemotional pathways between adult attachment and ego-resiliency. Individual Differences Research, 10, 141-152.

Carver, C. S., Scheier, M. F., \& Kumari Weintraub, J. (1989). Assessing coping strategies: A theoretically based approach. Journal of Personality and Social Psychology, 56, 267-283.

Cassidy, J. (1994). Emotion regulation: Influences of attachment relationships. Monographs of the Society for Research in Child Development, 59, 228-224.

Collins, N. L., Guichard, A. C., Ford, M. B., \& Feeney, B. C. (2004). Working models of attachment: new developments and emerging themes. In W. S. Rholes \& J. A. Simpson (Eds.), Adult Attachment: Theory, Research, and Clinical Implications (pp. 196-239). New York: Guilford Publications.

Compas, B. C., Jaser, S. S., Dunbar, J. P., Watson, K. H., Bettis, A. H., Gruhn, M. A., \& Williams, E. K. (2013). Coping and emotion regulation from childhood to early adulthood: Points of convergence and divergence. Australian Journal of Psychology, 66, 71-81. https://doi.org/10.1111/ajpy.12043.

Dykas, M. J., Woodhouse, S. S., Jones, J. D., \& Cassidy, J. (2014). Attachment-related biases in adolescents' memory. Child Development, 85, 2185-2201. https://doi.org/10.1111/cdev.12268.

Esbjørn, B. H., Bender, P. K., Reinholdt-Dunne, M. L., Munck, L. A., \& Ollendick, T. H. (2011). The development of anxiety disorders: Considering the contributions of attachment and emotion regulation. Clinical Child and Family Psychology Review, 15(2), 129-143. https://doi.org/10.1007/s10567-011-0105-4.

Field, A. (2013). Discovering statistics using IBM SPSS Statistics. Newcastle: Sage.

Folkman, S., \& Moskowitz, J. T. (2004). Coping: pitfalls and promise. Annual Review of Psychology, 55, 745-774.

Fonagy, P., \& Luyten, P. (2012). Psychodynamic models of personality. The Oxford handbook of personality disorders. New York: Oxford University Press.

Fraley, R. C., \& Shaver, P. R. (1997). Adult attachment and the suppression of unwanted thoughts. Journal of Personality and Social Psychology, 73(5), 1080-1091. https://doi.org/10.1037/0022-3514. 73.5.1080.

Fraley, R. C., Garner, J. P., \& Shaver, P. R. (2000). Adult attachment and the defensive regulation of attention and memory: Examining the role of preemptive and postemptive defensive processes. Journal of Personality and Social Psychology, 79, 816-826.

Frederickson, J. J., Messina, I., \& Grecucci, A. (2018). Dysregulated anxiety and dysregulating defenses: Toward an emotion regulation informed dynamic psychotherapy. Frontiers in Psychology, 9, 2054. https://doi.org/10.3389/fpsyg.2018.02054.

Fuendeling, J. M. (1998). Affect regulation as a stylistic process within adult attachment. Journal of Social and Personal Relationships, 15, 291-322.

Garnefski, N., \& Kraaij, V. (2007). The Cognitive Emotion Regulation Questionnaire. European Journal of Psychological Assessment, 23(3), 141-149.

Garnefski, N., Teerds, J., Kraaij, V., Legerstee, J., \& van den Kommer, T. (2004). Cognitive emotion regulation strategies and depressive symptoms: Differences between males and females. Personality and Individual Differences, 36, 267-276.

Garrison, A. M., Kahn, J. H., Sauer, E. M., \& Florczak, M. A. (2012). Disentangling the effects of depression symptoms and adult attachment on emotional disclosure. Journal of Counseling Psychology, 59, 230-239. https://doi.org/10.1037/a0026132.

Gouveia, T., \& Matos, P.M. (2011). Manual do Questionário de Vinculação ao Pai e à Mãe (QVPM). [Manual of the Father/ Mother Attachment Questionnaire] Porto: Centro de Psicologia da Universidade do Porto.
Gratz, K. L., \& Roemer, E. (2004). Multidimensional assessment of emotion regulation and dysregulation: Development, factor structure, and initial validation of the difficulties in emotion regulation scale. Journal of Psychopathology and Behavioral Assessment, 26, 41-54.

Gross, J. J. (2013). Emotion regulation: Taking stock and moving forward. Emotion, 13, 359-365. https://doi.org/10.1037/a0032135.

Gross, J. J., \& John, O. P. (2003). Individual differences in two emotion regulation processes: Implications for affect, relationships, and wellbeing. Journal of Personality and Social Psychology, 85, 348-362.

Gross, J. J., \& Thompson, R. A. (2007). Emotion regulation: Conceptual foundations. In J. J. Gross (Ed.), Handbook of emotion regulation (pp. 3-26). New York: The Guilford Press.

Hambleton, R. K., Merenda, P., \& Spielberger, C. (Eds.). (2005). Adapting educational and psychological tests for cross-cultural assessment. Hillsdale: Lawrence S. Erlbaum Publishers.

Hooper, D., Coughlan, J., \& Mullen, M. R. (2008). Structural equation modeling: Guidelines for determining model fit. The Electronic Journal of Business Research Methods, 6, 53-60.

John, O. P., \& Eng, J. (2014). Three approaches to individual differences in affect regulation: Conceptualizations, measures, and findings. In J. J. Gross (Ed.), Handbook of emotion regulation (pp. 321-345). New York: The Guilford Press.

Karreman, A., \& Vingerhoets, A. J. J. M. (2012). Attachment and wellbeing: The mediating role of emotion regulation and resilience. Personality and Individual Differences, 53, 821-826. https://doi. org/10.1016/j.paid.2012.06.014.

Kline, R. B. (2015). Principles and practice of structural equation modeling. New York: Guilford Publications.

Kullik, A., \& Petermann, F. (2013). Attachment to parents and peers as a risk factor for adolescent depressive disorders: the mediating role of emotion regulation. Child Psychiatry \& Human Development, 44(4), 537-535.

Lopez, F. G., \& Brennan, K. A. (2000). Dynamic processes underlying adult attachment organization: Toward an attachment theoretical perspective on the healthy and effective self. Journal of Counseling Psychology, 47, 283-300.

Low, R. S. T., Overall, N. C., Cross, E. J., \& Henderson, A. M. E. (2018). Emotion regulation, conflict resolution, and spillover on subsequent family functioning. Emotion. Advance online publication. https:// doi.org/10.1037/emo0000519.

Main, M. (1990). Cross-cultural studies of attachment organization: Recent studies, changing methodologies, and the concept of conditional strategies. Human Development, 33, 48-61.

Malik, S., Wells, A., \& Wittkowski, A. (2015). Emotion regulation as a mediator in the relationship between attachment and depressive symptomatology: A systematic review. Journal of Affective Disorders, 172, 428-444. https://doi.org/10.1016/j.jad.2014.10. 007.

Mallinckrodt, B., \& Wei, M. (2005). Attachment, social competencies, social support, and psychological distress. Journal of Counseling Psychology, 52, 358-367. https://doi.org/10.1037/0022-0167.52.3. 358.

Marôco, J. (2011). Análise estatística com o SPSS statistics [statistical analysis with SPSS statistics]. ReportNumber, Lda.

Martin, R. C., \& Dahlen, E. R. (2005). Cognitive emotion regulation in the prediction of depression, anxiety, stress, and anger. Personality and Individual Differences, 39(7), 1249-1260.

Matos, P. M. \& Costa, M. E. (2001). Father and mother attachment questionnaire. (unpublished manuscript). Faculdade de Psicologia e de Ciências da Educação da universidade do Porto.

Mikulincer, M., Shaver, P. R., \& Pereg, D. (2003). Attachment theory and affect regulation: The dynamics, development, and cognitive consequences of attachment-related strategies. Motivation and Emotion, $27,77-102$. 
Mikulincer, M., \& Shaver, P. R. (2007). Attachment processes and emotion regulation. In Attachment in Adulthood: Structure, Dynamics, and Change (pp. 188-218). New York: The Guilford Press.

Monti, J. D., \& Rudolph, K. D. (2014). Emotional awareness as a pathway linking adult attachment to subsequent depression. Journal of Counseling Psychology, 61, 374-382. https://doi.org/10.1037/ cou0000016.

Nolen-Hoeksema, S., Wisco, B. E., \& Lyubomirsky, S. (2008). Rethinking rumination. Perspectives on Psychological Science, 3(5), 400-424.

Nunnally, J. C., \& Bernstein, I. H. (1994). Psychometric theory. New York: McGraw-Hill.

Oatley, K., Keltner, D., \& Jenkins, J. M. (2006). Understanding emotions (2nd ed.). Oxford: Blackwell.

Otto, J. H., Döring-Seipel, E., Grebe, M., \& Lantermann, E.-D. (2001). Entwicklung eines Fragebogens zur Erfassung der wahrgenommenen emotionalen Intelligenz: Aufmerksamkeit auf, Klarheit und Beeinflussbarkeit von Emotionen [development of a questionnaire for measuring perceived emotional intelligence: Attention to, clarity, and repair of emotions]. Diagnostica, 47, 178-187. https://doi.org/10.1026//0012-1924.47.4.178.

Palmer, B. R., Gignac, G., Bates, T., \& Stough, C. (2003). Examining the structure of the trait Meta-mood scale. Australian Journal of Psychology, 55, 154-159. https://doi.org/10.1080/ 0004953042000298612.

Pascuzzo, K., Cyr, C., \& Moss, E. (2013). Longitudinal association between adolescent attachment, adult romantic attachment, and emotion regulation strategies. Attachment \& Human Development, 15, 83-103. https://doi.org/10.1080/14616734.2013.745713.

Patil, V. H., Surendra N. S., Mishra, S., \& Donavan, D. T. (2007). Parallel analysis engine to aid determining number of factors to fetain [Computer software]. Available from http://smishra.faculty.ku.edu/ parallelengine.htm.

Pedrosa, I., Suárez-Álvarez, J., Lozano, L. M., Muniz, J., \& GarcíaCueto, E. (2014). Assessing perceived emotional intelligence in adolescents new validity evidence of trait Meta-mood scale-24. Journal of Psychoeducational Assessment, 32, 737-746. https:// doi.org/10.1177/0734282914539238.

Potthoff, S., Garnefski, N., Miklósi, M., Ubbiali, A., DomínguezSánchez, F. J., Martins, E. C., et al. (2016). Cognitive emotion regulation and psychopathology across cultures: A comparison between six European countries. Personality and Individual Differences, 98, 218-224. https://doi.org/10.1016/j.paid.2016.04. 022.

Queirós, M. M., Fernández-Berrocal, P., Extremera, N., Carral, J. M., \& Queirós, P. S. (2005). Validação e fiabilidade da versão Portuguesa modificada da trait Meta- mood scale [validity and reliability of the modified Portuguese version of the trait Meta-mood scale]. Psicologia, Educação e Cultura, 9, 199-216.

Salovey, P., Mayer, M., Goldman, S. L., Turvey, C., \& Palfai, T. P. (1995). Emotional attention, clarity, and repair: Exploring emotional intelligence using the trait Meta-mood scale. In J. W. Pennebaker (Ed.), Emotion, disclosure, and health (pp. 125-154). Washington, D.C.: American Psychological Assn.

Siegel, J. P. (2013). Breaking the links in intergenerational violence: An emotional regulation perspective. Family Process, 52(2), 163-178. https://doi.org/10.1111/famp.12023.

Sroufe, L. A., \& Waters, E. (1977). Attachment as an organizational construct. Child Development, 48, 1184-1199.

Tabachnick, B. G., \& Fidell, L.S. (2007). Using multivariate statistics $\left(5^{\text {th }}\right.$ Ed.) Boston: Peason.

Thompson, R. A. (2008). Attachment-related mental representations: Introduction to the special issue. Attachment \& Human Development, 10, 1-12.

Treynor, W., Gonzalez, R., \& Nolen-Hoeksema, S. (2003). Rumination reconsidered: A psychometric analysis. Cognitive Therapy and Research, 27, 247-259.

Van Ijzendoorn, M. H., Schuengel, C., \& Bakermans-Kranenburg, M. J. (1999). Disorganized attachment in early childhood: meta-analysis of precursors, concomitants, and sequelae. Development and Psychopathology, 11(2), 225-250.

Wei, M., Vogel, D. L., Ku, T., \& Zakalik, R. A. (2005). Adult attachment, affect regulation, negative mood, and interpersonal problems: The mediating roles of emotional reactivity and emotional cutoff. Journal of Counseling Psychology, 52, 14-24. https://doi.org/10. 1037/0022-0167.52.1.14.

Wróbel, M., Finogenow, M., Szymańska, P., \& Laurent, J. (2019). Measuring positive and negative affect in a school-based sample: A polish version of the PANAS-C. Journal of Psychopathology and Behavioral Assessment, 41(4), 598-611. https://doi.org/10.1007/ s10862-019-09720-7.

Zimmer-Gembeck, M. J., Webb, H. J., Pepping, C. A., Swan, K., Merlo, O., Skinner, E. A., et al. (2017). Review: Is parent-child attachment a correlate of Children's emotion regulation and coping? International Journal of Behavioral Development, 41(1), 74-93. https://doi.org/10.1177/0165025415618276.

Publisher's Note Springer Nature remains neutral with regard to jurisdictional claims in published maps and institutional affiliations. 


\section{Terms and Conditions}

Springer Nature journal content, brought to you courtesy of Springer Nature Customer Service Center GmbH ("Springer Nature").

Springer Nature supports a reasonable amount of sharing of research papers by authors, subscribers and authorised users ("Users"), for smallscale personal, non-commercial use provided that all copyright, trade and service marks and other proprietary notices are maintained. By accessing, sharing, receiving or otherwise using the Springer Nature journal content you agree to these terms of use ("Terms"). For these purposes, Springer Nature considers academic use (by researchers and students) to be non-commercial.

These Terms are supplementary and will apply in addition to any applicable website terms and conditions, a relevant site licence or a personal subscription. These Terms will prevail over any conflict or ambiguity with regards to the relevant terms, a site licence or a personal subscription (to the extent of the conflict or ambiguity only). For Creative Commons-licensed articles, the terms of the Creative Commons license used will apply.

We collect and use personal data to provide access to the Springer Nature journal content. We may also use these personal data internally within ResearchGate and Springer Nature and as agreed share it, in an anonymised way, for purposes of tracking, analysis and reporting. We will not otherwise disclose your personal data outside the ResearchGate or the Springer Nature group of companies unless we have your permission as detailed in the Privacy Policy.

While Users may use the Springer Nature journal content for small scale, personal non-commercial use, it is important to note that Users may not:

1. use such content for the purpose of providing other users with access on a regular or large scale basis or as a means to circumvent access control;

2. use such content where to do so would be considered a criminal or statutory offence in any jurisdiction, or gives rise to civil liability, or is otherwise unlawful;

3. falsely or misleadingly imply or suggest endorsement, approval, sponsorship, or association unless explicitly agreed to by Springer Nature in writing;

4. use bots or other automated methods to access the content or redirect messages

5. override any security feature or exclusionary protocol; or

6. share the content in order to create substitute for Springer Nature products or services or a systematic database of Springer Nature journal content.

In line with the restriction against commercial use, Springer Nature does not permit the creation of a product or service that creates revenue, royalties, rent or income from our content or its inclusion as part of a paid for service or for other commercial gain. Springer Nature journal content cannot be used for inter-library loans and librarians may not upload Springer Nature journal content on a large scale into their, or any other, institutional repository.

These terms of use are reviewed regularly and may be amended at any time. Springer Nature is not obligated to publish any information or content on this website and may remove it or features or functionality at our sole discretion, at any time with or without notice. Springer Nature may revoke this licence to you at any time and remove access to any copies of the Springer Nature journal content which have been saved.

To the fullest extent permitted by law, Springer Nature makes no warranties, representations or guarantees to Users, either express or implied with respect to the Springer nature journal content and all parties disclaim and waive any implied warranties or warranties imposed by law, including merchantability or fitness for any particular purpose.

Please note that these rights do not automatically extend to content, data or other material published by Springer Nature that may be licensed from third parties.

If you would like to use or distribute our Springer Nature journal content to a wider audience or on a regular basis or in any other manner not expressly permitted by these Terms, please contact Springer Nature at

onlineservice@springernature.com 